\title{
ON APPROACH OF ESTIMATION OF VALUE OF RISKS DURING MANUFACTURING OF PRODUCTS
}

\section{E. L. Pankratov}

Nizhny Novgorod State University, 23 Gagarin Avenue, Nizhny Novgorod, 603950, Russia

Nizhny Novgorod State Technical University, 24 Minin Street, Nizhny Novgorod, 603950, Russia

\begin{abstract}
In modern economic theory, scientific and technological progress one consider different economic risks. The influence of scientific and technological progress on a particular sector of the economy appears in the creation of new products that have important competitive advantages over existing ones, or in the modification (modernization) of existing products. Often, new products based on new (innovative) technologies. However, technological superiority requires well-timed modernization of production and staff training, that is, significant financial and organizational investments. At the same time, the rejection of the transition to innovative technologies can lead to tangible losses in market positions or even

${ }^{*}$ Corresponding author.

E-mail address: elp2004@mail.ru (E. L. Pankratov).

Copyright @ 2021 Scientific Advances Publishers

2020 Mathematics Subject Classification: 91-10, 34A06.

Submitted by Jianqiang Gao.

Received January 15, 2021; Revised March 10, 2021

This work is licensed under the Creative Commons Attribution International License (CC BY 3.0).

http://creativecommons.org/licenses/by/3.0/deed.en_US

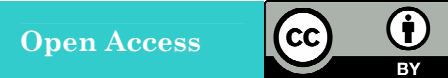


to a complete cessation of the organization. In this paper, we introduce a model for estimations influence of risks on development of industrial enterprises. An analytical approach for analyzing the influence of various parameters on the proceeds has been introduced.

Keywords: risks, industrial enterprises, analytical modelling.

\section{Introduction}

In modern economic theory, scientific and technological progress considers as one of the relevant factors of long-term economic growth. The influence of scientific and technological progress on a particular sector of the economy appears in the creation of new products that have important competitive advantages over existing ones, or in the modification (modernization) of existing products. Often, new products based on new (innovative) technologies. However, technological superiority requires well-timed modernization of production and staff training, that is, significant financial and organizational investments. At the same time, the rejection of the transition to innovative technologies can lead to tangible losses in market positions or even to a complete cessation of the organization. Currently, one of the important examples of markets, which characterizing by the crowding out of some products by others that are more attractive from a technological point of view, is the market for information and telecommunication technologies (the market for data transmission services). For most managers of enterprises that are suppliers of products and investors, the issue of prognosis of risk attracted an interest [1-6]. One could be distinguish the following types of risk: risk of overproduction of products (in this case, it is attracted an interest prognosis of demand of manufactured products); the risk of under-supply of materials (due to unreliable suppliers, transport problems, etc.); lack of qualified workers, etc. One of the quantitative criteria the impact of different risks is the change in profit margin with the manifestation of various risks: in the case of overproduction occur 
losses due to cost overruns of materials used, excessive wages, etc. In this paper, we introduced a quantitative approach for prognosis of risk on manufacturing process. We also considers an analytical approach for solving of the equations, which were used in the considered model. In this case of under-production of products one can find a reason to discuss the lost profit.

\section{Method of Solution and Discussion}

Now we consider changing of the profit of an industrial enterprise with time. Value of the profit determined by the quantity of produced products and the quantity of expenses. In this situation, one can write the following differential equation:

$$
\frac{d Q(t)}{d t}=N(t)-a(t)-b(t)-c(t)-d(t)-e(t)-f(t)-g(t) .
$$

Description of the required values using differential equations gives a possibility to take into account their nonstationary variations $[7,8]$ in comparison with the stationary description [9-12]. We used the following values in the Equation (1): $t$ is the current time; $Q(t)$ is the profit of industrial enterprises; $N(t)$ is the quantity of products; $a(t)$ is the transport cost; $b(t)$ is the energetic cost; $c(t)$ is the cost of personal (salary, training and medical expenses); $d(t)$ is the raw material cost; $e(t)$ is the research cost (investigation of market; investigations for development of technologies including investigations to take into account amortization); $f(t)$ is the tax expenses; $g(t)$ is the waste disposal costs.

Initial condition for the function $Q(t)$ could be written as

$$
Q(0)=0 .
$$


Solution of Equation (1) with account condition (2) could be written as

$$
\begin{aligned}
Q(t)= & \int_{0}^{t} N(\tau) d \tau-\int_{0}^{t} a(\tau) d \tau-\int_{0}^{t} b(\tau) d \tau-\int_{0}^{t} c(\tau) d \tau-\int_{0}^{t} d(\tau) d \tau \\
& -\int_{0}^{t} e(\tau) d \tau-\int_{0}^{t} f(\tau) d \tau-\int_{0}^{t} g(\tau) d \tau .
\end{aligned}
$$

Now we will consider dependences of profit on different parameters. Figures 1 and 2 show dependences of profit on several parameters for their constant values. Framework the considered model profit could be negative. In this situation, one can assume these negative values of profit as damage. Increasing of transport, energetic and other costs leads to decreasing of profit framework dependences of considered function on these parameters. Decreasing of profit with time depends on analogous changing of considered costs. Analysis of dependences of profit on parameters shows, that existing so combinations of parameters, which corresponds to (i) profit of enterprises always existing and increasing; (ii) profit of enterprises decreasing and manufacturing of products gradually losing profitability; and (iii) production is temporarily unprofitable and gradually becomes profitable with the development of the enterprise. During manufacturing of products, special cases that are natural from an economic point of view are also fulfilled: (i) with a well-chosen strategy, there will be a stable growth in the manufacturing of products; with a less well-chosen strategy (ii) the production of products ceases due to market saturation or because of the too high cost of products, (iii) there may also be a delay in the production of products due to the need to prepare the manufacturing process. 


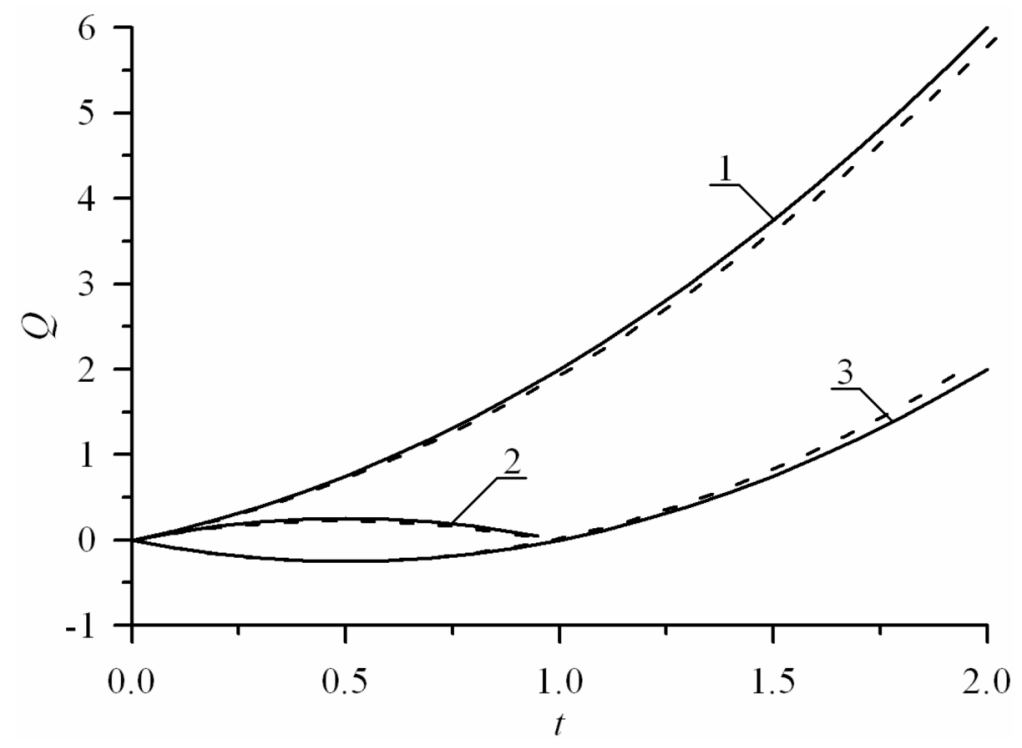

Figure 1. Qualitative dependencies of profit on time. Solid lines are the analytical results. Dashed lines are the results of numerical simulation.

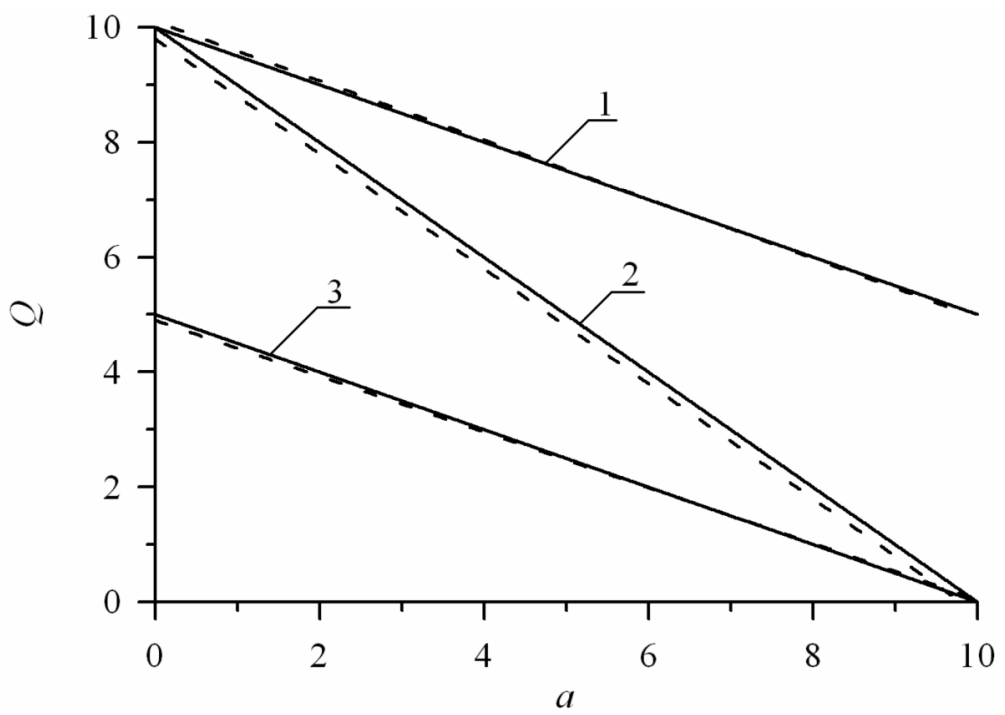

Figure 2. Qualitative dependencies of profit on quantity of transportation costs. Solid lines are the analytical results. Dashed lines are the results of numerical simulation. 
Now we consider the effect of the dependence of a several of considered parameters on time. As examples, we considered a linear change in time of the quantity of manufactured products, dues, transportation costs, as well as personnel costs (personnel training can be an example of such expenses). As a result, qualitatively similar dependencies of profit on the considered parameters were obtained in comparison with their constant values. At the same time, a quantitative change in profit was find in accordance with the types of change in parameters: increasing of quantity of manufactured products leads to an increasing of profit; increasing of other considered parameters leads to a decreasing of profit.

\section{Conclusion}

In this paper, we introduce a model for prognosis of risks on industrial activity. We also introduce an analytical approach to solve equations, which were used in our model, taking into account possible changes of its parameters on time (transport costs, energetic costs, research, etc.). The analysis of the introduced model has been done. As a result of the analysis we obtain following limiting cases, which are native from economical point of view: (i) if the product manufacturing strategy is successfully chosen, the company will have a stable profit; with less well-chosen strategies, the enterprise (ii) will have temporary losses related to the need to organize the manufacturing of products, or (iii) the manufacturing of products will stop due to market saturation or too high cost of the products manufactured. In the end, the results of the performed analysis allow the company to determine the rational way of further functioning and the choice of the most appropriate way of strategic development. 


\section{References}

[1] D. T. Cassidy, Risk-neutral pricing of European call options: A specious concept, Journal of Mathematical Finance 8(3) (2018), 335-348.

DOI: https://doi.org/10.4236/jmf.2018.82022

[2] S. Gamba-Santamaria, O. F. Jaulin-Mendez, L. F. Melo-Velandia and C. A. Quicazán-Moreno, Comparison of methods for estimating the uncertainty of value at risk, Studies in Economics and Finance 33(4) (2017), 595-624.

DOI: https://doi.org/10.1108/SEF-03-2016-0055

[3] D. Kumar and S. Maheswaran, Value-at-risk and expected shortfall using the unbiased extreme value volatility estimator, Studies in Economics and Finance 34(4) (2017), 506-526.

DOI: https://doi.org/10.1108/SEF-03-2016-0061

[4] F. Unbehaun and F. Fuerst, Cap rates and risk: A spatial analysis of commercial real estate, Studies in Economics and Finance 35(1) (2018), 25-43.

DOI: https://doi.org/10.1108/SEF-11-2016-0267

[5] I. Tlemsani and R. Matthews, Conventional banks risk diversification: A case for Islamic finance, Theoretical Economics Letters 9(6) (2019), 1967-1980

DOI: https://doi.org/10.4236/tel.2019.96125

[6] K. Goel and S. Oswal, Value at risk models in Indian markets: A predictive ability evaluation study, Theoretical Economics Letters 9(8) (2019), 2824-2838.

DOI: https://doi.org/10.4236/tel.2019.98177

[7] E. L. Pankratov, An analytical approach to the analysis of industrial enterprise activity, Journal of Coupled Systems and Multiscale Dynamics 6(2) (2018), 154-157.

DOI: https://doi.org/10.1166/jcsmd.2018.1147

[8] E. L. Pankratov, Model for prognosis of economic growth: Accounting of influence of the environment, Global Economy Journal 19(1) (2019); Article 1950007.

DOI: https://doi.org/10.1142/S2194565919500076

[9] J. Das and D. C. Nath, Burr distribution as an actuarial risk model and the computation of some of its actuarial quantities related to the probability of ruin, Journal of Mathematical Finance 6(1) (2016), 213-231.

DOI: https://doi.org/10.4236/jmf.2016.61019

[10] Chien W. Wu and W. Zhan Hung, Real national income average growth rate: A novel economic growth and social fair evaluation index, Economics Research International (2015); Article ID 678927.

DOI: https://doi.org/10.1155/2015/678927 
[11] A. V. Trachuk and N. V. Linder, Innovative activity of industrial enterprises: Measurement and effectiveness evaluation, Strategic Decisions and Risk Management 10(2) (2019), 108-121.

DOI: https://doi.org/10.17747/2618-947x-2019-2-108-121

[12] N. M. Abdikeev, Yu. S. Bogachev, A. A. Losev and S. A. Tolkachev, Multivariate model of analysis and assessment of the competitiveness of socio-economic systems, Strategic Decisions and Risk Management 10(2) (2019), 156-165.

DOI: https://doi.org/10.17747/2618-947x-2019-2-156-165 